\title{
Physiological effects of an oil rich in $\gamma$-linolenic acid on hepatic fatty acid oxidation and serum lipid levels in genetically hyperlipidemic mice
}

\author{
Takashi Ide* and Izumi Origuchi \\ Department of Food and Nutrition, Faculty of Human Life, Jumonji University, 2-1-28 Sugasawa, Niiza, Saitama 352-8510, Japan
}

(Received 17 June, 2018; Accepted 29 July, 2018; Published online 15 November, 2018)

\begin{abstract}
We investigated the physiological activity of an oil rich in $\gamma$-linolenic acid of evening primrose origin (containing $42.6 \% \gamma$-linolenic acid) affecting hepatic fatty acid metabolism, and serum lipid levels in genetically hyperlipidemic mice deficient in apolipoprotein $E$ expression. Male apolipoprotein E-deficient mice (BALB/c.KOR/ StmSlc-Apoe ${ }^{\text {shl}}$ ) were fed experimental diets containing $100 \mathrm{~g} / \mathrm{kg}$ of palm oil (saturated fat), safflower oil (rich in linoleic acid), $\gamma$ linolenic acid oil (rich in $\gamma$-linolenic acid), or fat mixtures composed of safflower and $\gamma$-linolenic acid oils (65:35 and 30:70, w/w) for 20 days. $\gamma$-Linolenic acid oil, compared with palm and safflower oils, strongly and dose-dependently increased the activity and mRNA levels of hepatic fatty acid oxidation enzymes. In general, safflower and $\gamma$-linolenic acid oils, compared with palm oil, reduced the activity and mRNA levels of lipogenic enzymes. However, these oils were equivalent in reducing the parameters of lipogenesis, excluding malic enzyme and pyruvate kinase. The diets containing safflower and $\gamma$-linolenic acid oils, compared with the palm oil diet, significantly decreased serum triacylglycerol and cholesterol levels. The decreases were greater with $\gamma$-linolenic acid oil than with safflower oil. $\gamma$-Linolenic acid oil exerted strong serum lipid-lowering effects in apolipoprotein E-deficient mice apparently through the changes in hepatic fatty acid metabolism.
\end{abstract}

Key Words: apolipoprotein E-deficient mice, $\gamma$-linolenic acid, hepatic fatty acid oxidation, hepatic lipogenesis, serum lipids

$\mathrm{M}$ any studies have found that various types of polyunsaturated fatty acids (PUFAs) influence hepatic fatty acid oxidation and synthesis. Physiological activities of respective PUFA affecting hepatic fatty acid synthesis and oxidation differ considerably from each other. Regarding the physiological activities of $\gamma$-linolenic acid (GLA), a $n-6$ trienoic acid, one report stated that a fungal oil rich in GLA, compared with soybean oil, increased carnitine palmitoyltransferase activity and the peroxisomal $\beta$-oxidation rate in the rat liver. ${ }^{(1)}$ Furthermore, it has been demonstrated that borage oil rich in GLA, compared with a saturated fat (palm oil) and fats rich in linoleic acid but devoid of GLA, increases hepatic peroxisomal fatty acid oxidation, ${ }^{(2,3)}$ and the activities of carnitine palmitoyltransferase $\mathrm{e}^{(2,3)}$ and acyl-CoA oxidase ${ }^{(2)}$ in rats. In addition, borage oil increased mRNA levels of some peroxisomal enzymes involved in hepatic fatty acid oxidation but was ineffective in increasing mRNA levels of mitochondrial fatty acid oxidation enzymes. ${ }^{(3)}$ Regarding the physiological activity of GLA affecting hepatic lipogenesis, dietary oil rich in GLA compared with palm oil reduced the activities of enzymes involved in lipogenesis in the rat liver. However, the reducing effects were comparable with those observed with an oil rich in linoleic acid but devoid of GLA. ${ }^{(2)}$ Studies have indicated that oils rich in GLA lower serum cholesterol ${ }^{(1,4-6)}$ and triacylglycerol levels in rats. ${ }^{(2,7,8)}$ It is probable that up-regulation of hepatic fatty acid oxidation is the mechanism underlying the hypolipidemic effects of oils rich in GLA. However, a considerable number of studies ${ }^{(3,9,10)}$ have failed to observe serum lipid-lowering effects of oils rich in GLA. Therefore, careful evaluation of lipid-lowering propensity of oils rich in GLA is still required. Up-regulation of uncoupling protein 1 in brown adipose tissue rather than of hepatic fatty acid oxidation may be the mechanism underlying the attenuation of body fat accumulation in rats fed oils rich in GLA. ${ }^{(1,3)}$

Previous studies using rats as experimental animals found that dietary GLA enhanced hepatic fatty acid oxidation, but its serum lowering propensity was controversial. Animal models of hyperlipidemia are useful for clarifying the physiological activity of dietary factors affecting serum lipid levels. In relation to this, Fan et $a l .{ }^{(11)}$ evaluated the anti-atherogenic effects of evening primrose oil rich in GLA in apolipoprotein E (apoE) knock-out mice with C57BL/6 genetic background. They demonstrated that dietary GLA was effective in attenuating progression of atherosclerosis, but it did not lower serum lipid levels in apoE knock-out mice. There is the possibility that apoE knock-out mice with C57BL/6 genetic background are not suitable for evaluating the physiological activities of dietary PUFAs affecting serum lipid levels. Indeed, previous studies ${ }^{(12,13)}$ reported that fish oil abundant in eicosapentaenoic and docosahexaenoic acids (EPA and DHA) failed to affect serum lipid levels in apoE knock-out mice even though many animal experiments using rats ${ }^{(14,15)}$ and mice ${ }^{(16-18)}$ resulted in potent serum lipid lowering effects of fish oil or EPA and DHA. Given the above, we herein investigated the physiological activity of an oil rich in GLA of evening primrose origin that affects hepatic fatty acid metabolism and serum and liver lipid profiles using hyperlipidemic BALB/c.KOR/StmSlc-Apoe $e^{\text {shl }}$ mice deficient in the expression of apoE. The congenic apoE-deficient mice with the genetic background of BALB/c were established by transferring the apoE gene mutation found in Japanese wild mice of the KOR genetic background through repeated backcrossing. We demonstrated that $A p o e^{\text {shl }}$ mice with the genetic background of $\mathrm{BALB} / \mathrm{c}$ in contrast to apoE knock-out mice with $\mathrm{C} 57 \mathrm{BL} / 6$ genetic background was useful for evaluating different effects of fish oil and EPA/DHA ethylesters affecting hepatic fatty acid metabolism and serum lipid profiles. ${ }^{(19)} \mathrm{We}$ herein clarified that the oil rich in GLA of evening primrose origin is a potent inducer of hepatic fatty acid oxidation and that it markedly affects serum lipid levels in Apoe $e^{\text {shl }}$ mice.

*To whom correspondence should be addressed. E-mail: t-ide@jumonji-u.ac.jp 


\section{Materials and Methods}

Animals and diets. Male BALB/c.KOR/StmSlc-Apoe $e^{\text {shl }}$ mice were obtained from Japan SLC, Inc., Hamamatsu, Japan at 4-5 weeks of age. Mice were housed individually in suspended wirebottomed stainless-steel cages in a room with controlled temperature $\left(21-23^{\circ} \mathrm{C}\right)$, humidity $(55-65 \%)$, and lighting (lights on from 07:00 to 19:00), and fed commercial chow. After 12 days of acclimatization, mice were randomly divided into five groups with equal mean body weight consisting of 7 animals each and fed purified experimental diets for 20 days. Experimental diets contained $100 \mathrm{~g} / \mathrm{kg}$ of either palm oil, safflower oil, an oil rich in $\gamma$-linolenic acid (GLA oil), or fat mixtures composed of safflower and GLA oils (65:35 and 30:70, w/w). GLA oil containing $42.6 \%$ GLA prepared by the selective hydrolysis of evening primrose oil containing $10.5 \%$ GLA using lipase of Candida cylindracea origin was donated by Tama Biochemical Co., Ltd., Tokyo, Japan. The fatty acid compositions of the dietary fats are shown in Table 1. The purified experimental diets contained $(\mathrm{g} / \mathrm{kg})$ : casein, 200; dietary fat, 100; corn starch, 150; cellulose, 20; mineral mixture, ${ }^{(20)} 35$; vitamin mixture, ${ }^{(20)} 10$; L-cystine, 3 ; choline bitartrate, 2.5 and sucrose, 479.5. Animals had free access to the diets and water during the experimental period until they were euthanized. This animal experiment was approved by the review board of animal ethics of Jumonji University (approval number 1510; issued on January 5, 2016), and we followed the University's guidelines for the care and use of experimental animals.

Enzyme assays. At the end of the experiment, mice were anesthetized by isoflurane and euthanized by bleeding from the inferior vena cava from 09:00 to 11:00, after which the livers were quickly excised. Approximately $0.5 \mathrm{~g}$ of each liver was homogenized in $5 \mathrm{ml}$ of $0.25 \mathrm{M}$ sucrose containing $1 \mathrm{mM}$ EDTA and $3 \mathrm{mM}$ Tris- $\mathrm{HCl}$ ( $\mathrm{pH} \mathrm{7.2)}$, and $3 \mathrm{ml}$ of the homogenates were centrifuged at $200,000 \mathrm{~g}$ for $30 \mathrm{~min}$. The activities of enzymes involved in fatty acid oxidation and synthesis were measured using total homogenates and the $200,000 \mathrm{~g}$ supernatant of the liver homogenate, respectively. ${ }^{(19)}$

RNA analyses. Liver RNA was extracted by the method of Chomczynski and Sacchi. ${ }^{(21)}$ The quantity and quality of the RNA

Table 1. Fatty acid compositions of dietary fats

\begin{tabular}{cccc}
\hline $\begin{array}{l}\text { Fatty acids }(\mathrm{g} / 100 \mathrm{~g} \\
\text { total fatty acid) }\end{array}$ & \multicolumn{3}{c}{ Dietary fats } \\
\cline { 2 - 4 } $10: 0$ & 0.2 & 0.0 & SLA oil \\
\hline $12: 0$ & 0.7 & 0.0 & 0.0 \\
$16: 0$ & 44.0 & 5.2 & 4.1 \\
$18: 0$ & 1.2 & 1.2 & 1.3 \\
$18: 1 n-9$ & 39.3 & 9.5 & 5.6 \\
$18: 2 n-6$ & 14.7 & 84.1 & 46.4 \\
$18: 3 n-6$ & 0.0 & 0.0 & 42.6 \\
\hline
\end{tabular}

were assessed by measuring absorbance at 260, 280, and $320 \mathrm{~nm}$, and by electrophoresis on $1.0 \%$ agarose gels. mRNA abundance was measured using the SYBR Green real-time PCR method as described previously. ${ }^{(22)}$ The reaction specificity for this method was verified by a melting curve analysis. mRNA abundance was calculated as a ratio to the mRNA abundance of $\beta$-actin in each cDNA sample and expressed as a fold change, assigning a value of 1 for mice fed a diet containing $100 \mathrm{~g} / \mathrm{kg}$ of palm oil.

Analyses of lipids and carnitine. Liver lipids were extracted and purified, and triacylglycerol, phospholipid, and cholesterol concentrations in the lipid extract were determined as described previously. ${ }^{(23)}$ The serum high-density lipoprotein (HDL) fraction was prepared by precipitating apolipoprotein B-containing lipoproteins using polyethylene glycol (average molecular weight of 6,000 , Sigma-Aldrich Japan Co., Tokyo, Japan). ${ }^{(24)}$ Serum triacylglycerol, cholesterol, phospholipid, and free fatty acid concentration, as well as cholesterol and phospholipid level in the serum HDL fraction were analyzed using commercial enzyme kits (Wako Pure Chemical, Osaka, Japan). Cholesterol and phospholipid concentrations in the very low- and low-density lipoprotein (VLDL + LDL) fractions were calculated by subtracting the values in the HDL fraction from those in unfractionated serum samples. The hepatic concentration of carnitine was analyzed by the method of Pearson et al. ${ }^{(25)}$

Statistical analysis. Microsoft Excel add-in software (Excel Statistics 2015, Social Survey Research Information Co., Tokyo, Japan) was used for statistical analyses. Data were expressed as means and their standard errors. The constancy of the variance and normality of the distribution of the observations were evaluated using Levene's test and the Kolmogorov-Smirnov test, respectively. If variances were heterogeneous and/or the distributions were not normal, they were transformed logarithmically. These transformations were successful in rendering the variance of the observations constant and the distribution of data normal, and hence the transformed values were used for subsequent statistical evaluations. Data were analyzed using one-way ANOVA and Tukey's post-hoc test to evaluate significant differences of all means. Differences were considered significant when $p<0.05$.

\section{Results}

Growth parameters and liver weights. Fat types did not significantly affect food intake or growth among the groups (Table 2). Liver weights were the same between animals fed palm oil or safflower oil as the sole dietary fat source. GLA oil dosedependently increased this value. All values in mice fed diets containing different levels of GLA oil were significantly higher than those in the animals fed diets containing palm or safflower oil as the sole dietary fat source.

Activity and mRNA levels of enzymes involved in hepatic fatty acid oxidation. A diet containing safflower oil as the sole dietary fat source, compared with palm oil diet, slightly but significantly increased the activity of carnitine acyltransferase

Table 2. Effects of dietary fat on growth parameters and liver weight

\begin{tabular}{|c|c|c|c|c|c|}
\hline & \multicolumn{5}{|c|}{ Dietary fat $(100 \mathrm{~g} / \mathrm{kg})$} \\
\hline & \multirow{2}{*}{ Palm oil } & \multicolumn{4}{|c|}{ Safflower oil:GLA oil } \\
\hline & & $100: 0$ & $65: 35$ & $30: 70$ & $0: 100$ \\
\hline Food intake (g/day) & $4.68 \pm 0.10$ & $4.80 \pm 0.16$ & $4.50 \pm 0.07$ & $4.48 \pm 0.15$ & $4.40 \pm 0.13$ \\
\hline \multicolumn{6}{|l|}{ Body weight (g) } \\
\hline 0 day & $22.6 \pm 0.5$ & $22.7 \pm 0.5$ & $22.7 \pm 0.6$ & $23.0 \pm 0.7$ & $22.8 \pm 0.8$ \\
\hline 18 day & $27.4 \pm 0.5$ & $27.7 \pm 0.9$ & $28.3 \pm 0.7$ & $28.2 \pm 0.8$ & $27.8 \pm 0.5$ \\
\hline Growth (g/20 days) & $4.8 \pm 0.2$ & $5.0 \pm 0.6$ & $5.5 \pm 0.5$ & $5.2 \pm 0.5$ & $5.0 \pm 0.5$ \\
\hline Liver weight (g/100 g body weight) & $6.13 \pm 0.13$ & $6.13 \pm 0.18$ & $6.42^{*, \#} \pm 0.1$ & $7.09 * . \# \pm 0.1$ & $7.62^{*, \#} \pm 0.2$ \\
\hline
\end{tabular}

Values are mean $\pm \mathrm{SEM}, n=7$. ${ }^{*} p<0.05$ vs mice fed $100 \mathrm{~g} / \mathrm{kg}$ palm oil diet. ${ }^{*} p<0.05$ vs mice fed $100 \mathrm{~g} / \mathrm{kg}$ safflower oil diet. 

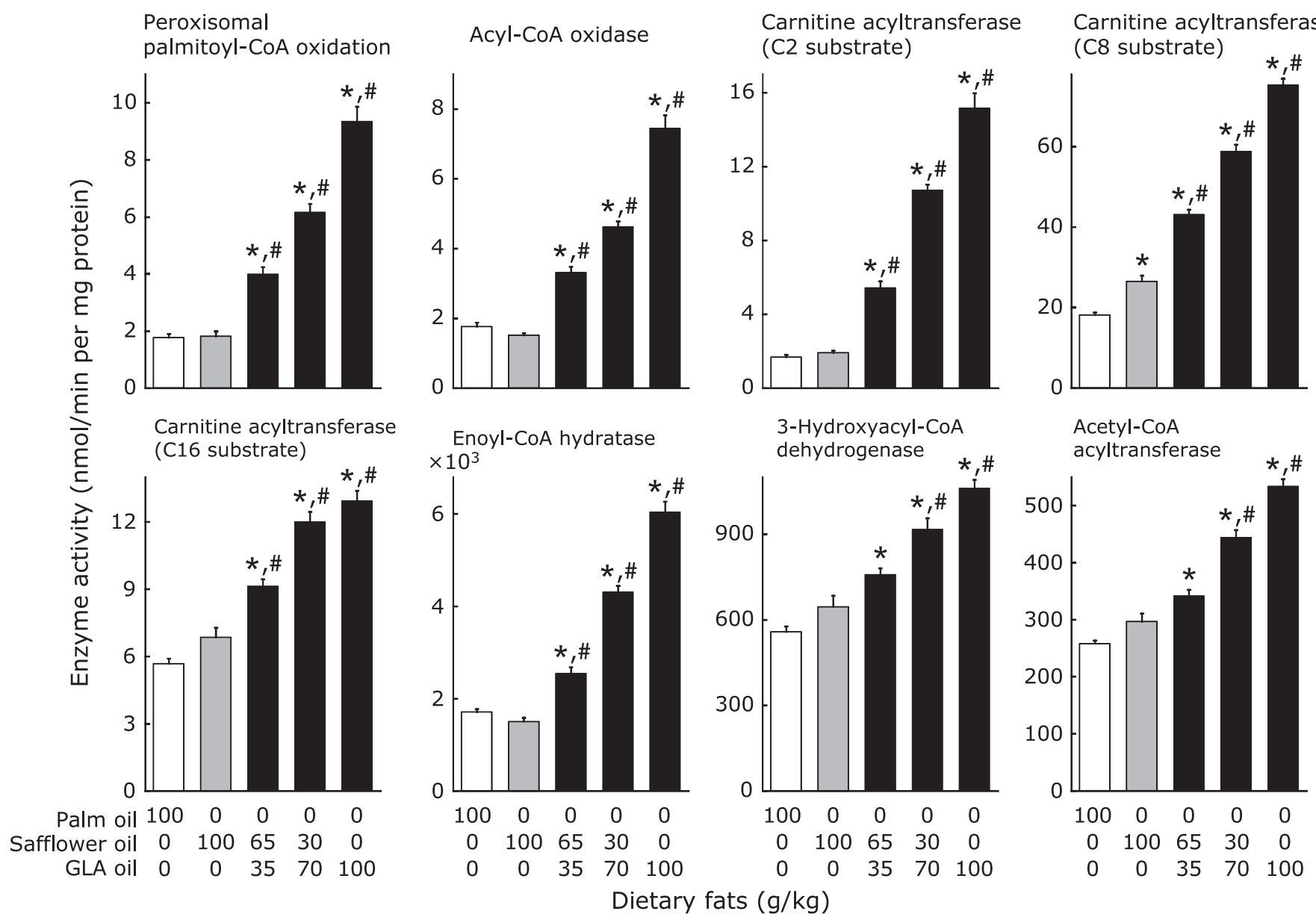

Fig. 1. Effects of dietary fat on the activity of enzymes involved in fatty acid oxidation in the mouse liver. Carnitine acyltransferase activities were measured using three types of acyl-CoA substrates differing in carbon chain lengths (acetyl- (C2), octanoyl- (C8), and palmitoyl-CoAs (C16)). Values are mean \pm SEM, $n=7 .{ }^{*} p<0.05$ vs mice fed $100 \mathrm{~g} / \mathrm{kg}$ palm oil diet. ${ }^{\#} p<0.05$ vs mice fed $100 \mathrm{~g} / \mathrm{kg}$ safflower oil diet. GLA oil, an oil rich in $\gamma$-linolenic acid.

measured using octanoyl-CoA as a substrate (Fig. 1). However, this diet, compared with palm oil diet, was ineffective in modifying the activities of other enzymes involved in fatty acid oxidation. GLA oil dose-dependently increased the activities of various enzymes involved in fatty acid oxidation. GLA oil, even at $35 \mathrm{~g} / \mathrm{kg}$, compared with the diet containing either palm or safflower oil as the sole dietary fat source, significantly increased the values, except for in two instances. The activities of 3-hydroxyacyl-CoA dehydrogenase and acetyl-CoA acyltransferase in mice fed the $35 \mathrm{~g} / \mathrm{kg}$ GLA oil diet were not significantly different from those in animals fed a diet containing safflower oil as the sole dietary fat source.

Figure 2 shows the mRNA levels of mitochondrial fatty acid oxidation enzymes. Dietary GLA oil, even at $35 \mathrm{~g} / \mathrm{kg}$, compared with palm and safflower oils, significantly increased the mRNA levels of various mitochondrial fatty acid oxidation enzymes, except for carnitine palmitoyltransferase 1a. These values further increased as dietary levels of GLA oil increased. However, the response of the mRNA level of carnitine palmitoyltransferase 1a to dietary fats was considerably different from that of the other mitochondrial fatty acid oxidation enzymes. The type of dietary fat did not influence the mRNA levels of this enzyme.

Figure 3 shows mRNA levels of peroxisomal enzymes involved in hepatic fatty acid oxidation. The mRNA levels of the peroxisomal membrane protein, peroxisomal biogenesis factor $11 \alpha$, as well as those of microsomal cyp4a10 involved in $\omega$-oxidation of fatty acids and CD36 molecule, a plasma membrane protein that plays a role in the cellular uptake of fatty acids from the blood stream, are also shown in this figure. Again, GLA oil, compared with palm and safflower oils, caused large and dose-dependent increases in the mRNA levels of these proteins.

We also measured mRNA levels of peroxisome proliferatoractivated receptor $\alpha$ (PPAR $\alpha)$, but dietary fat-dependent changes were not observed. The values were $1.00 \pm 0.07$ and $0.956 \pm 0.097$ for mice fed diets containing palm or safflower oil as a sole fat source, respectively. The levels in mice fed diets containing varying concentrations of GLA oil were $1.11 \pm 0.026,1.21 \pm 0.08$, and $1.04 \pm 0.06$ for the animals fed diets containing 35,70 , and $100 \mathrm{~g} / \mathrm{kg}$ GLA oil, respectively.

Activity and mRNA levels of enzymes involved in hepatic lipogenesis. The activity levels of fatty acid synthase, ATP citrate lyase, glucose 6-phosphate dehydrogenase, and pyruvate kinase were lower in mice fed polyunsaturated fat diets than in those fed a palm oil diet (Table 3). GLA oil, compared with safflower oil, did not affect the activities of fatty acid synthase, ATP citrate lyase, or glucose 6-phosphate dehydrogenase. In contrast, GLA oil markedly decreased the activities of pyruvate kinase; these values in animals fed the diets containing 70 and $100 \mathrm{~g} / \mathrm{kg}$ of GLA oil were less than one-half of those in animals fed a diet containing safflower oil as the sole fat source. The situation was considerably different for malic enzyme. A diet containing safflower oil as the sole fat source, compared with palm oil diet, significantly decreased the activity of malic enzyme. However, the values progressively increased as the dietary level 
Carnitine acetyltransferase
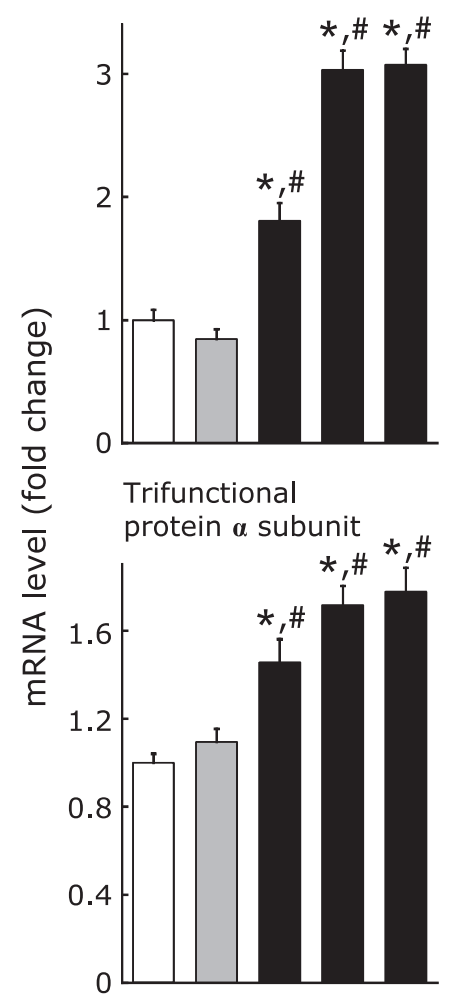

Palm oil $\begin{array}{lllll}100 & 0 & 0 & 0 & 0\end{array}$

Safflower oil $0 \quad \begin{array}{lllll}100 & 65 & 30 & 0\end{array}$

$\begin{array}{llllll}\text { GLA oil } & 0 & 0 & 35 & 70 & 100\end{array}$
Carnitine

palmitoyltransferase $1 a$
Carnitine

palmitoyltransferase $1 b$
Carnitine

palmitoyltransferase 2
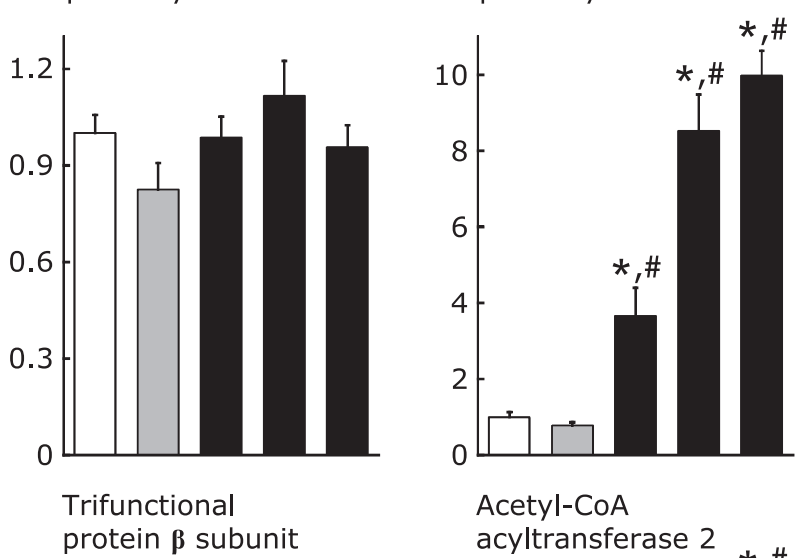

\section{Acetyl-CoA}

acyltransferase 2
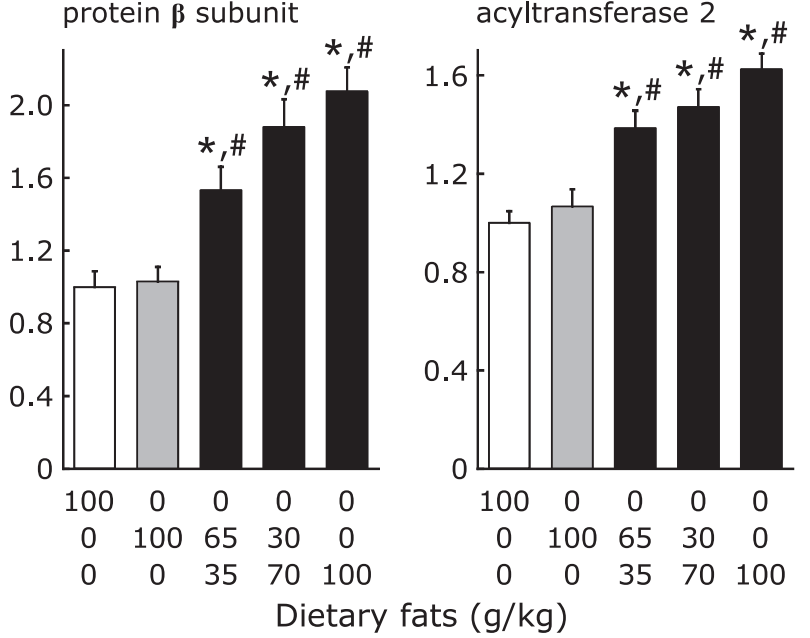

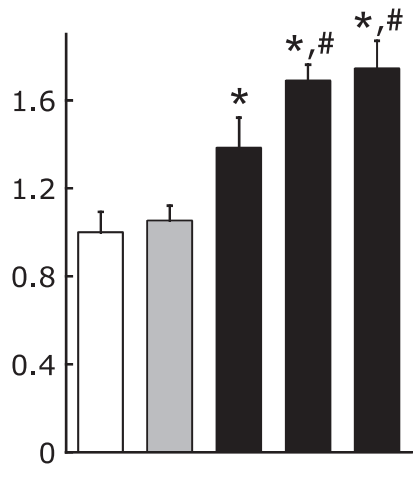

Enoyl-CoA delta isomerase 1

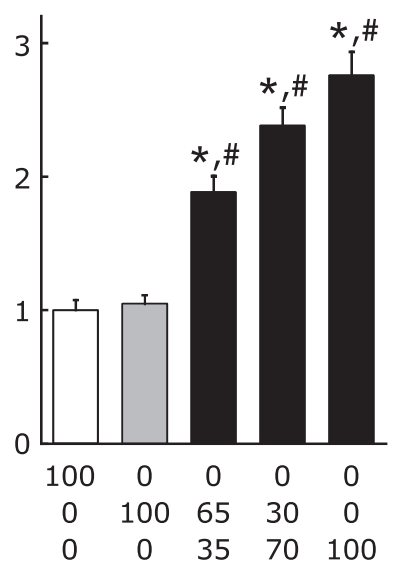

Fig. 2. Effects of dietary fat on the mRNA levels of mitochondrial enzymes involved in fatty acid oxidation in the mouse liver. Values are mean $\pm \mathrm{SEM}, n=7$. ${ }^{*} p<0.05$ vs mice fed $100 \mathrm{~g} / \mathrm{kg}$ palm oil diet. ${ }^{*} p<0.05$ vs mice fed $100 \mathrm{~g} / \mathrm{kg}$ safflower oil diet. GLA oil, an oil rich in $\gamma$-linolenic acid.

of GLA oil increased. As a result, the activity level of this enzyme in mice fed a diet containing GLA oil as the sole fat source became comparable to that observed with a palm oil diet.

Table 4 shows the mRNA levels of proteins related to hepatic lipogenesis. There are two types of acetyl-CoA carboxylase, $\alpha$ and $\beta$. The $\alpha$, but not $\beta$ form, functions in long-chain fatty acid synthesis in the cytosol. Several isoforms of pyruvate kinase and malic enzyme have been identified in mammals. Pyruvate kinase liver and red blood cell (Pklr) and malic enzyme 1 encode the enzymes involved in hepatic lipogenesis. Glucose-6-phosphate dehydrogenase X-linked (G6pdx) encodes glucose 6-phosphate dehydrogenase. Experimental diets containing safflower and/or GLA oils, compared with a palm oil diet, decreased the mRNA levels of acetyl-CoA carboxylase $\alpha$, fatty acid synthase, G6pdx, and Pklr. However, GLA oil and safflower oils reduced these values to a similar extent, except for Pklr mRNA levels. A diet containing safflower oil as the sole dietary fat source caused a $30 \%$ decrease in mRNA levels of Pklr compared with a palm oil diet. Replacement of safflower oil by GLA oil caused progressive additional decreases in the value. Responses of malic enzyme 1 mRNA levels to dietary fats were considerably different from those of other lipogenic enzymes. A diet containing safflower oil as the sole fat source, compared with a palm oil diet, significantly decreased this value. However, replacement of safflower oil by GLA oil dose-dependently increased the value. Consequently, the values observed with the diets containing 70 and $100 \mathrm{~g} / \mathrm{kg}$ of GLA oil became comparable to those in the animals fed a palm oil diet.
We also measured the mRNA levels of enzymes involved in the desaturation of fatty acids (stearoyl-CoA desaturase 1, and fatty acid desaturase 1 and 2). The responses of these mRNA levels to dietary fats resembled those observed for the mRNA levels of malic enzyme 1. A safflower oil diet, compared with a palm oil diet, significantly decreased these values. However, the replacement of safflower oil by GLA oil dose-dependently increased the values. As a result, the values in mice fed diets containing $100 \mathrm{~g} / \mathrm{kg}$ of GLA oil were similar to or even significantly higher than those in mice fed a palm oil diet. We also measured mRNA levels of transcription factors involved in the regulation of lipogenesis. Although the type of dietary fat did not affect the mRNA levels of sterol regulatory element binding transcription factor 1 variant 2 , alternatively known as sterol regulatory element binding protein-1c (SREBP-1c) or carbohydrate response element binding protein $\alpha$ $(\mathrm{ChREBP} \alpha)$, polyunsaturated fats compared with palm oil significantly reduced the mRNA levels of ChREBP $\beta$. However, the values were the same among mice fed diets containing safflower oil alone or containing varying amounts of GLA oil.

Hepatic carnitine concentrations, and mRNA levels of proteins involved in carnitine transport and synthesis.

Diets containing GLA oil compared with diets containing palm or safflower oil as the sole fat source significantly increased the hepatic carnitine concentration (Fig. 4). Changes in hepatic carnitine concentrations by dietary fats paralleled those in the mRNA levels of carnitine transporter (solute carrier family 22, member 5), which mediates carnitine transport across the plasma membrane. 


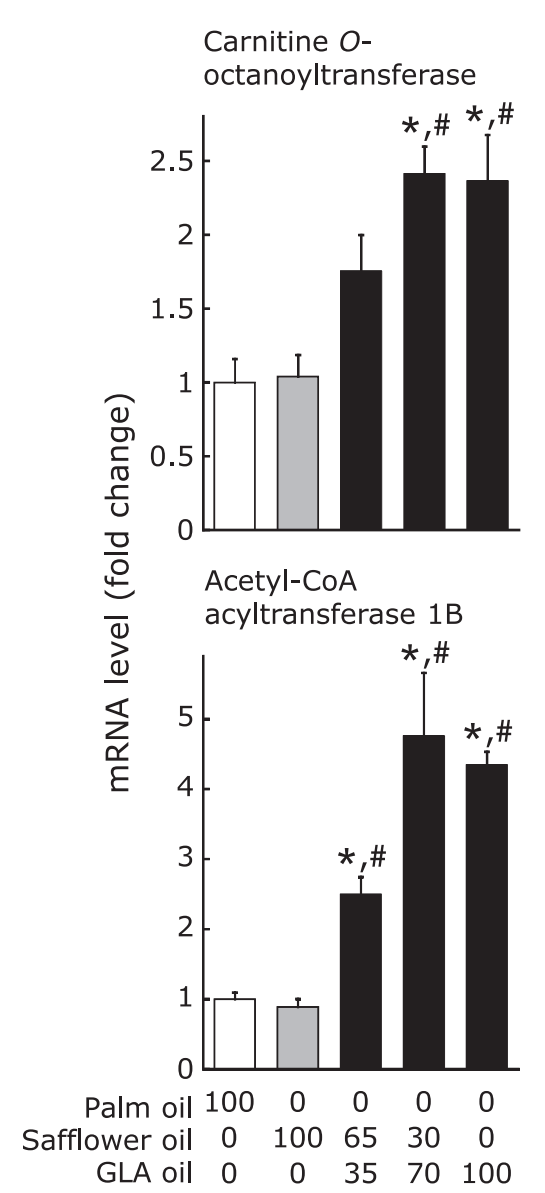

\section{Acyl-CoA oxidase 1}

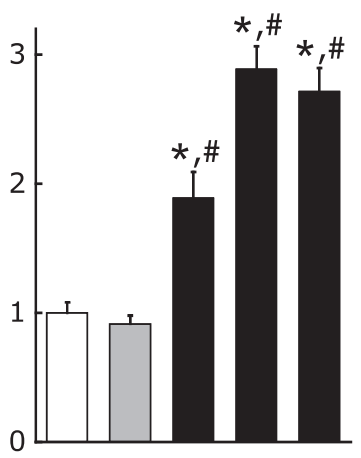

Peroxisomal biogenesis factor $11 \alpha$

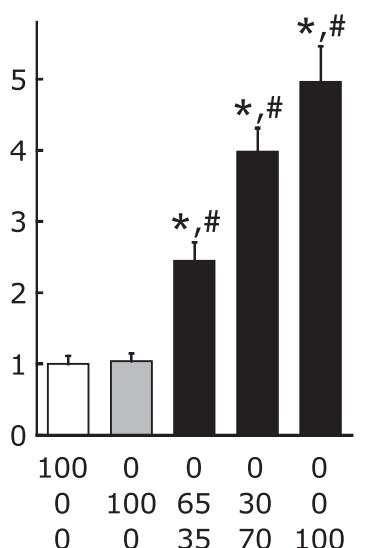

Enoyl-CoA, hydratase/

3-hydroxyacyl-CoA

dehydrogenase

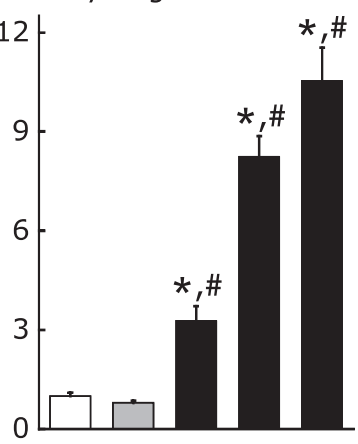

Cyp4a10

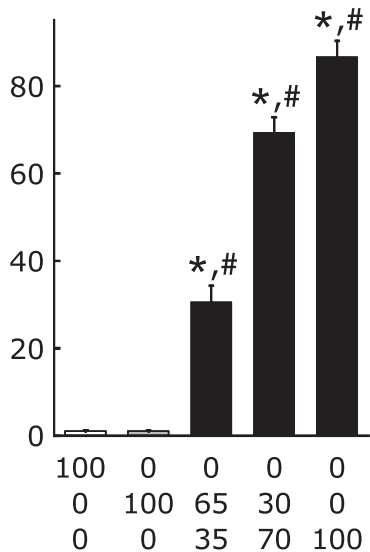

Cd36 molecule

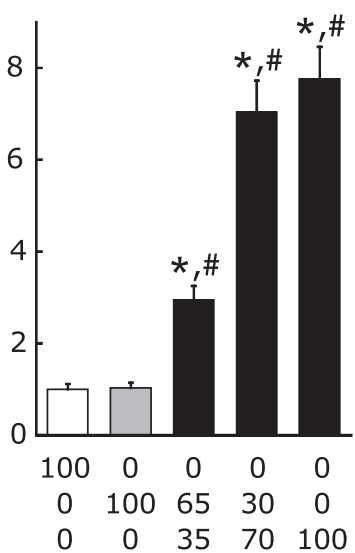

Dietary fats $(\mathrm{g} / \mathrm{kg})$

Fig. 3. Effects of dietary fat on the mRNA levels of peroxisomal enzymes involved in fatty acid oxidation, peroxisomal membrane protein peroxin $11 \alpha$, microsomal cyp4a10, and plasma membrane cd36 in the mouse liver. Values are mean $\pm \mathrm{SEM}, n=7$. ${ }^{*} p<0.05 \mathrm{vs}$ mice fed $100 \mathrm{~g} / \mathrm{kg}$ palm oil diet. ${ }^{\#} p<0.05$ vs mice fed $100 \mathrm{~g} / \mathrm{kg}$ safflower oil diet. GLA oil, an oil rich in $\gamma$-linolenic acid.

Table 3. Effects of dietary fat on the activities of lipogenic enzymes

\begin{tabular}{|c|c|c|c|c|c|}
\hline \multirow{3}{*}{ Enzymes } & \multicolumn{5}{|c|}{ Dietary fat (100 g/kg) } \\
\hline & \multirow{2}{*}{ Palm oil } & \multicolumn{4}{|c|}{ Safflower oil:GLA oil } \\
\hline & & $100: 0$ & $65: 35$ & $30: 70$ & $0: 100$ \\
\hline Fatty acid synthase & $36.7 \pm 2.5$ & $20.4 * \pm 1.4$ & $18.9 * \pm 2.3$ & $20.1 * \pm 1.3$ & $19.9 * \pm 1.4$ \\
\hline ATP-Citrate lyase & $32.1 \pm 3.2$ & $13.7 * \pm 1.5$ & $10.8 * \pm 1.2$ & $10.3 * \pm 0.6$ & $9.27 * \pm 0.75$ \\
\hline Glucose 6-phosphate dehydrogenase & $11.9 \pm 0.8$ & $7.14^{*} \pm 0.61$ & $6.89 * \pm 0.30$ & $6.54^{*} \pm 0.12$ & $6.23 * \pm 0.34$ \\
\hline Malic enzyme & $301 \pm 21$ & $180 * \pm 16$ & $195 * \pm 13$ & $245 \pm 23$ & $313^{\#} \pm 19$ \\
\hline Pyruvate kinase & $742 \pm 46$ & $560 * \pm 39$ & $365^{*, \#} \pm 11$ & $256^{*, \#} \pm 15$ & $247 *, \pm 7$ \\
\hline
\end{tabular}

Values are mean \pm SEM, $n=7 .{ }^{*} p<0.05$ vs mice fed $100 \mathrm{~g} / \mathrm{kg}$ palm oil diet. ${ }^{*} p<0.05$ vs mice fed $100 \mathrm{~g} / \mathrm{kg}$ safflower oil diet.

Although the changes were attenuated, diets containing GLA oil, compared with diets containing palm or safflower oil as the sole fat source, increased the mRNA levels of genes encoding enzymes involved in carnitine biosynthesis (trimethyllysine hydroxylase, $\varepsilon$, aldehyde dehydrogenase 9 , subfamily $A 1$, and butyrobetaine $(\gamma)$, 2-oxoglutarate dioxygenase 1 , and the values for all three enzymes were significantly higher in mice fed the $100 \mathrm{~g} / \mathrm{kg}$ GLA oil diet than in those fed the diet containing $100 \mathrm{~g} / \mathrm{kg}$ of palm or safflower oil as the sole fat source.

Serum and liver concentrations of lipids. The diets containing polyunsaturated fats (safflower and GLA oils), compared with a palm oil diet, significantly decreased serum triacylglycerol levels (Table 5). Decreases were greater with GLA oil than with safflower oil. Indeed, the levels were significantly lower in animals fed diets containing 70 or $100 \mathrm{~g} / \mathrm{kg}$ of GLA oil than in those fed a diet containing $100 \mathrm{~g} / \mathrm{kg}$ of safflower oil as a sole fat source. All polyunsaturated fat diets, compared with a palm oil diet, also significantly decreased serum cholesterol levels. In addition, the levels were lower in animals fed diets containing 35$100 \mathrm{~g} / \mathrm{kg}$ of GLA oil than in those fed a diet containing $100 \mathrm{~g} / \mathrm{kg}$ of safflower oil as the sole fat source. Cholesterol levels in the HDL fraction were the same between mice fed the diets containing palm or safflower oil as the sole fat source. However, diets containing varying amounts of GLA oil, compared with the diets 


\begin{tabular}{|c|c|c|c|c|c|}
\hline \multirow{3}{*}{ Genes } & \multicolumn{5}{|c|}{ Dietary fat $(100 \mathrm{~g} / \mathrm{kg})$} \\
\hline & \multirow{2}{*}{ Palm oil } & \multicolumn{4}{|c|}{ Safflower oil:GLA oil } \\
\hline & & $100: 0$ & $65: 35$ & $30: 70$ & $0: 100$ \\
\hline Acetyl-CoA carboxylase $\alpha$ & $1.00 \pm 0.07$ & $0.659 * \pm 0.063$ & $0.688 * \pm 0.029$ & $0.753 * \pm 0.047$ & $0.624 * \pm 0.032$ \\
\hline Fatty acid synthase & $1.00 \pm 0.08$ & $0.476 * \pm 0.067$ & $0.545 * \pm 0.053$ & $0.636 * \pm 0.042$ & $0.534 * \pm 0.057$ \\
\hline ATP citrate lyase & $1.00 \pm 0.09$ & $0.693 * \pm 0.094$ & $0.568 * \pm 0.049$ & $0.673^{*} \pm 0.063$ & $0.539 * \pm 0.048$ \\
\hline Glucose-6-phosphate dehydrogenase X-linked & $1.00 \pm 0.09$ & $0.638 * \pm 0.061$ & $0.599 * \pm 0.035$ & $0.574^{*} \pm 0.015$ & $0.602 * \pm 0.039$ \\
\hline Malic enzyme 1 & $1.00 \pm 0.09$ & $0.621 * \pm 0.067$ & $0.731 \pm 0.050$ & $1.03^{\#} \pm 0.11$ & $1.10^{\#} \pm 0.08$ \\
\hline Pyruvate kinase liver and red blood cell & $1.00 \pm 0.06$ & $0.701 * \pm 0.081$ & $0.467 *, \# \pm 0.042$ & $0.394^{*, \#} \pm 0.024$ & $0.330 *, \# \pm 0.025$ \\
\hline Stearoyl-CoA desaturase 1 & $1.00 \pm 0.16$ & $0.249 * \pm 0.055$ & $0.261 * \pm 0.031$ & $0.673^{\#} \pm 0.090$ & $0.689^{\#} \pm 0.092$ \\
\hline Fatty acid desaturase 1 & $1.00 \pm 0.09$ & $0.659 * \pm 0.044$ & $0.822 \pm 0.036$ & $1.23^{\#} \pm 0.050$ & $1.19^{\#} \pm 0.070$ \\
\hline Fatty acid desaturase 2 & $1.00 \pm 0.06$ & $0.593 * \pm 0.036$ & $0.902 \pm 0.063$ & $1.33^{*, \#} \pm 0.080$ & $1.11^{\#} \pm 0.07$ \\
\hline SREBP-1C & $1.00 \pm 0.13$ & $0.847 \pm 0.192$ & $0.720 \pm 0.060$ & $0.911 \pm 0.104$ & $0.837 \pm 0.096$ \\
\hline $\mathrm{ChRBP} \alpha$ & $1.00 \pm 0.04$ & $0.949 \pm 0.060$ & $0.989 \pm 0.077$ & $1.01 \pm 0.07$ & $0.937 \pm 0.060$ \\
\hline ChRBP $\beta$ & $1.00 \pm 0.06$ & $0.619 * \pm 0.035$ & $0.548 * \pm 0.042$ & $0.549 * \pm 0.066$ & $0.465^{*} \pm 0.039$ \\
\hline
\end{tabular}

mRNA levels are expressed as a fold change, assigning a value of 1 for mice fed a diet containing $100 \mathrm{~g} / \mathrm{kg}$ of palm oil. Values are mean \pm SEM, $n=7$. ${ }^{*} p<0.05$ vs mice fed $100 \mathrm{~g} / \mathrm{kg}$ palm oil diet. " $p<0.05$ vs mice fed $100 \mathrm{~g} / \mathrm{kg}$ safflower oil diet.

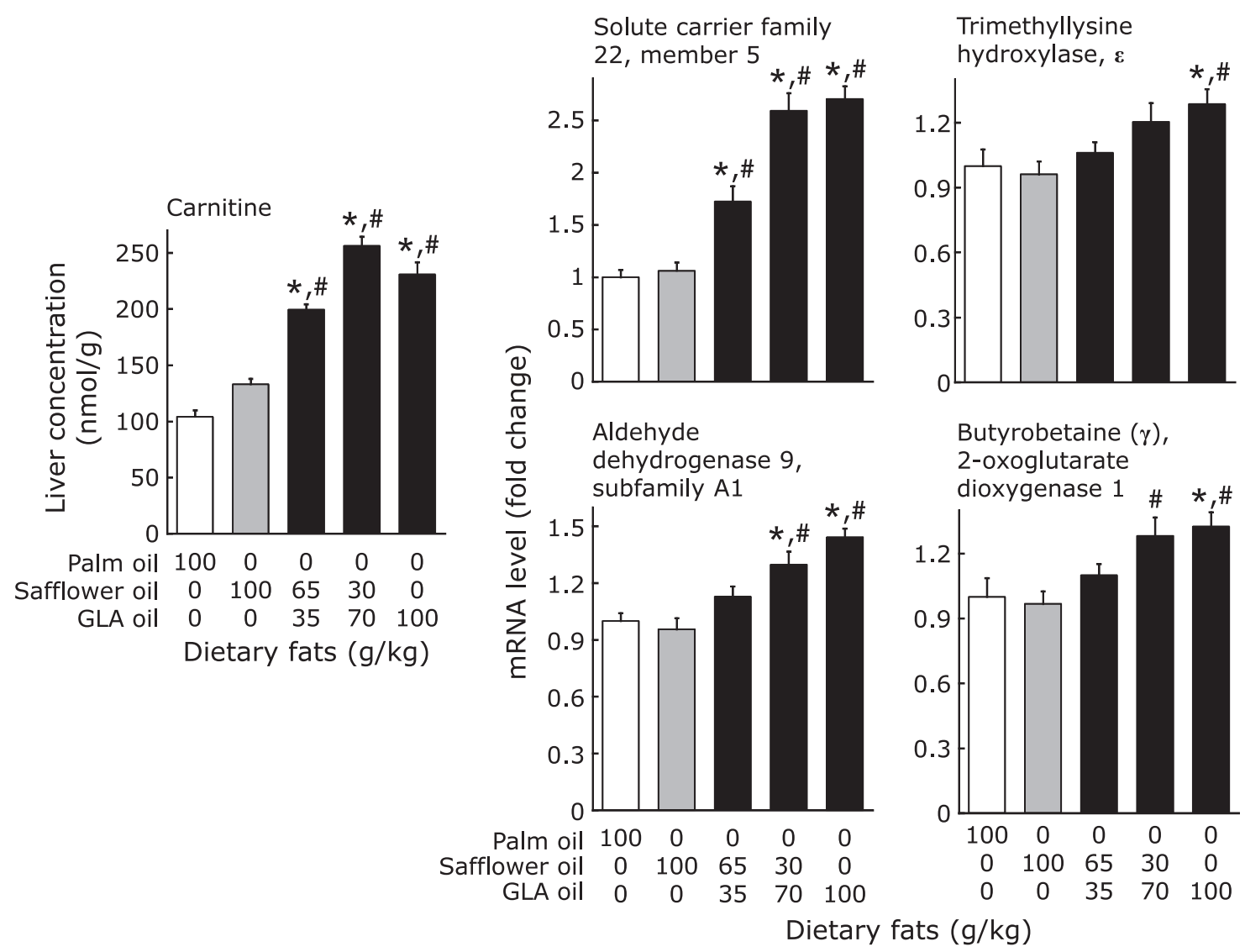

Fig. 4. Effects of dietary fat on carnitine concentrations, and the mRNA levels of carnitine transporter and enzymes involved in carnitine biosynthesis in the mouse liver. Values are mean $\pm \mathrm{SEM}, n=7 .{ }^{*} p<0.05 \mathrm{vs}$ mice fed $100 \mathrm{~g} / \mathrm{kg}$ palm oil diet. ${ }^{\#} p<0.05 \mathrm{vs}$ mice fed $100 \mathrm{~g} / \mathrm{kg}$ safflower oil diet. GLA oil, an oil rich in $\gamma$-linolenic acid.

containing palm or safflower oil as the sole fat source, significantly increased the HDL-cholesterol level. Conversely, the diets containing GLA oil, compared with palm or safflower oil diets, markedly reduced cholesterol concentrations in the fraction containing both VLDL and LDL. Again, polyunsaturated fat diets, compared with a palm oil diet, significantly decreased the serum phospholipid concentration. However, all the diets containing GLA oil, compared with a diet containing $100 \mathrm{~g} / \mathrm{kg}$ of safflower oil as the sole fat source, failed to affect this value. HDL-phospholipid levels were similar between animals fed diets containing palm oil or safflower oil as the sole fat source. All diets containing GLA oil, compared with diets containing palm or 
Table 5. Effects of dietary fat on the lipid levels in the serum and the liver

\begin{tabular}{|c|c|c|c|c|c|}
\hline & \multicolumn{5}{|c|}{ Dietary fat $(100 \mathrm{~g} / \mathrm{kg})$} \\
\hline & \multirow{2}{*}{ Palm oil } & \multicolumn{4}{|c|}{ Safflower oil:GLA oil } \\
\hline & & 100:0 & $65: 35$ & $30: 70$ & $0: 100$ \\
\hline \multicolumn{6}{|l|}{ Serum lipids $(\mu \mathrm{mol} / \mathrm{dl})$} \\
\hline Triacylglycerol & $374 \pm 27$ & $238^{*} \pm 18$ & $185^{*} \pm 16$ & $157^{*, \#} \pm 9$ & $161^{*, \#} \pm 6$ \\
\hline Cholesterol & $1,309 \pm 90$ & $691 * \pm 28$ & $546^{*, \# \pm 17}$ & $510^{*, \#} \pm 20$ & $511^{*, \#} \pm 27$ \\
\hline HDL-cholesterol & $173 \pm 9$ & $159 \pm 9$ & $211^{*, \#} \pm 9$ & $256^{*, \#} \pm 8$ & $230^{*, \#} \pm 9$ \\
\hline VLDL + LDL-cholesterol & $1,136 \pm 91$ & $532 * \pm 26$ & $335^{*, \#} \pm 14$ & $254^{*, \#} \pm 13$ & $281^{*, \#} \pm 28$ \\
\hline Phospholipid & $488 \pm 14$ & $278^{*} \pm 5$ & $273^{*} \pm 9$ & $321 * \pm 13$ & $328^{*} \pm 12$ \\
\hline HDL-phospholipid & $143 \pm 8$ & $129 \pm 7$ & $175^{*, \#} \pm 6$ & $218^{*, \#} \pm 3$ & $198^{*, \#} \pm 4$ \\
\hline VLDL + LDL-phospholipid & $345 \pm 17$ & $149 * \pm 4$ & $98.5^{*, \#} \pm 11$ & $104^{*} \pm 11$ & $130 * \pm 14$ \\
\hline Free fatty acids & $150 \pm 8$ & $106 \pm 2$ & $118 \pm 9$ & $98.9 * \pm 9.3$ & $90.4^{*} \pm 6$ \\
\hline \multicolumn{6}{|l|}{ Liver lipids $(\mu \mathrm{mol} / \mathrm{g})$} \\
\hline Triacylglycerol & $61.1 \pm 7.6$ & $43.4 \pm 5.5$ & $39.8^{*} \pm 4.5$ & $35.0 * \pm 3.3$ & $33.7^{*} \pm 3.2$ \\
\hline Cholesterol & $6.88 \pm 0.46$ & $6.24 \pm 0.27$ & $4.28^{*, \#} \pm 0.16$ & $3.58^{*, \#} \pm 0.12$ & $3.69 *, \# \pm 0.14$ \\
\hline Phospholipid & $38.3 \pm 0.7$ & $40.5 \pm 0.8$ & $45.7^{*, \#} \pm 1.4$ & $45.7^{*, \#} \pm 1.1$ & $46.9 *, \# \pm 0.8$ \\
\hline
\end{tabular}

Values are mean $\pm \mathrm{SEM}, n=7$. ${ }^{*} p<0.05$ vs mice fed $100 \mathrm{~g} / \mathrm{kg}$ palm oil diet. ${ }^{*} p<0.05$ vs mice fed $100 \mathrm{~g} / \mathrm{kg}$ safflower oil diet.

safflower oil as the sole fat source, significantly increased the values. The diets containing safflower and GLA oils, compared with a palm oil diet, greatly reduced the concentrations of VLDL + LDL-phospholipids. Among the mice fed polyunsaturated fat diets, a significant difference was only observed between mice fed a diet containing $100 \mathrm{~g} / \mathrm{kg}$ of safflower oil and those fed a diet containing $35 \mathrm{~g} / \mathrm{kg}$ of GLA oil and $65 \mathrm{~g} / \mathrm{kg}$ of safflower oil in combination. The value was significantly higher in the former than in the latter. Serum free fatty acid levels were lower in mice fed diets containing $70 \mathrm{~g} / \mathrm{kg}$ and $100 \mathrm{~g} / \mathrm{kg}$ of GLA oil than in those fed a palm oil diet.

In relation to the observed serum lipid concentrations, we measured hepatic mRNA levels of apolipoprotein AI, a major apolipoprotein of HDL. The values were $1.00 \pm 0.04$ and $0.862 \pm$ 0.067 for mice fed diets containing palm or safflower oil as a sole fat source, respectively. The levels were slightly but significantly lower in mice fed diets containing varying concentrations of GLA oil $(0.808 \pm 0.026,0.770 \pm 0.030$, and $0.807 \pm 0.040$ for mice fed diets containing 35,70 , and $100 \mathrm{~g} / \mathrm{kg}$ of GLA oil, respectively) than in those fed a palm oil diet. However, these values were not significantly different from the value in mice fed a diet containing safflower oil as a sole fat source.

The diets containing 35-100 g/kg of GLA oil, compared with a palm oil diet, significantly decreased the hepatic triacylglycerol concentrations, whereas a diet containing $100 \mathrm{~g} / \mathrm{kg}$ of safflower oil as the sole fat source did not. However, no significant differences were observed in this parameter among the four groups of mice fed polyunsaturated fat diets. A diet containing $100 \mathrm{~g} / \mathrm{kg}$ of safflower oil, compared with a palm oil diet, did not affect hepatic concentrations of cholesterol or phospholipid. All the diets containing varying concentrations of GLA oil, compared with diets containing palm or safflower oil as a sole fat source, significantly reduced hepatic concentrations of cholesterol and increased the values of phospholipids. However, these values were similar among mice fed the three diets containing different levels of GLA oil.

\section{Discussion}

Effects of GLA oil on hepatic fatty acid oxidation and carnitine metabolism. Previous studies demonstrated that fungal oil ${ }^{(1)}$ and borage oil ${ }^{(2,3)}$ rich in GLA increased the activity and mRNA levels of enzymes involved in hepatic fatty acid oxidation in rats (Wistar or Sprague-Dawley strain). GLA oil greatly increased hepatic fatty acid oxidation in $A p o e^{\text {shl }}$ mice in the present study. The changes were considerably exaggerated with $A_{p o e^{\text {shl }}}$ mice in the present study than with rats in the previous studies. For example, a diet containing $100 \mathrm{~g} / \mathrm{kg}$ of GLA oil, compared with diets containing palm or safflower oil as a sole fat source, increased the peroxisomal fatty acid oxidation rate by 5.1-5.3-fold in the present study. The effects were markedly attenuated in the previous study using Wistar rats, ${ }^{(1)}$ in which a fungal oil containing $25.3 \%$ GLA at a dietary level of $40 \mathrm{~g} / \mathrm{kg}$ compared with soybean oil increased the value by 1.3 -fold. In an experiment using Sprague-Dawley rats, borage oil containing $25.7 \%$ GLA at a dietary level of $150 \mathrm{~g} / \mathrm{kg}$, compared with palm and safflower oils, increased the value by 1.3 - to 1.4 -fold. ${ }^{(2)}$ In another experiment using Sprague-Dawley rats and borage oil containing $24.6 \%$ GLA as well as GLA-enriched borage oil containing $46.5 \%$ GLA at a dietary level of $200 \mathrm{~g} / \mathrm{kg}$, compared with safflower oil, increased peroxisomal fatty acid oxidation rats by $1.2-1.4$-fold. ${ }^{(3)}$ Therefore, the sensitivity of the hepatic fatty acid oxidation pathway to dietary GLA may be considerably different between mice and rats. Alternatively, the fatty acid oxidation pathway in Apoeshl mice compared with in other mouse strains may have a unique propensity to respond to dietary GLA. As experimental conditions differed considerably among these studies, careful examinations are still required to draw a definite conclusion. Dietary GLA not only increased the peroxisomal fatty acid oxidation rate but also enhanced the activities of various enzymes involved in fatty acid oxidation in the present study. A previous study using rats as experimental animals reported that dietary GLA increased mRNA levels of peroxisomal enzymes but did not affect those of mitochondrial enzymes. ${ }^{(3)}$ However, in the present study, dietary GLA greatly increased the mRNA levels of peroxisomal and mitochondrial enzymes involved in fatty acid oxidation in Apoe ${ }^{\text {shl }}$ mice. Peroxisome proliferator-activated receptor $\alpha(\mathrm{PPAR} \alpha)$ is known to be involved in regulating gene expression of hepatic fatty acid oxidation enzymes. ${ }^{(26)}$ Dietary GLA oil conceivably up-regulated hepatic fatty acid oxidation through the activation of PPAR $\alpha$. Indeed, GLA oil not only increased the mRNA expression of mitochondrial and peroxisomal enzymes involved in hepatic $\beta$-oxidation, but also increased mRNA levels of microsomal cyp4a10 involved in $\omega$-oxidation of fatty acids and of plasma membrane CD36 molecule, which plays a role in the cellular uptake of fatty acids from the blood circulation. Available evidence ${ }^{(27,28)}$ indicated that these genes are also targeted by PPAR $\alpha$ to increase their expression. 
We found that GLA oil increased hepatic concentrations of carnitine. As changes in carnitine concentrations paralleled those in carnitine transporter mRNA levels, increased uptake from the blood stream may be the primary cause for changes in hepatic carnitine concentrations. In addition, GLA oil, compared with palm and safflower oils, moderately but significantly increased the mRNA levels of enzymes involved in carnitine biosynthesis. Therefore, changes in carnitine biosynthesis may also be involved in GLA oil-dependent changes in hepatic carnitine concentrations. Previous studies suggested that PPAR $\alpha$ also controls gene expression of the carnitine transporter ${ }^{(29)}$ and enzymes involved in carnitine biosynthesis. ${ }^{(30,31)}$

Effects of GLA oil on hepatic fatty acid synthesis. In the present study, safflower oil and GLA oil, as well as mixtures of these oils, compared with palm oil, decreased the activities and mRNA levels of fatty acid synthase, ATP-citrate lyase and glucose 6-phosphate dehydrogenase. Both safflower and GLA oils, compared with palm oil, lowered pyruvate kinase activity and mRNA levels of Pklr. GLA oil was more effective than safflower oil in reducing these values. Moreover, GLA oil relative to safflower oil increased the activity and mRNA levels of malic enzyme, and increased mRNA levels of stearoyl-CoA desaturase 1. Similar changes were also observed in mRNA levels of fatty acid desaturase 1 and 2 involved in the metabolism of PUFAs. These conflicting results may be due to the combined effects of signals mediated by several transcription factors. The transcription factors SREBP-1c and ChREBP are master regulators of hepatic lipogenesis. ${ }^{(32)}$ In addition, PPAR $\alpha$ targets some genes involved in lipogenesis and fatty acid desaturation. Regarding the role of SREBP-1 in the PUFA-mediated suppression of hepatic lipogenesis, previous studies reported that dietary PUFAs decreased the nuclear content of the mature form of this transcription factor. ${ }^{(33)}$ However, this was not necessarily accompanied by a decrease in the mRNA expression of SREBP-1. Although dietary PUFA-dependent changes were not observed in the mRNA levels of SREBP-1 in the present study, diets containing safflower and/or GLA oil may have decreased the nuclear content of the mature form of this transcription factor, and hence decreased the mRNA and activity levels of lipogenic enzymes. There are two isoforms of ChREBP, $\alpha$ and $\beta{ }^{(32)}$ and ChREBP $\alpha$ is mainly localized in the cytosol. Upon stimulation, cytosolic ChREBP $\alpha$ is translocated into the nucleus, and up-regulates genes involved in glucose metabolism and lipogenesis. ChREBP $\alpha$ also targets the ChREBP $\beta$ gene to stimulate its expression. Transcriptional activity to stimulate gene expression of enzymes involved in glucose metabolism and lipogenesis is much higher with the $\beta$ isoform than with the $\alpha$ isoform. In the present study, diets containing PUFAs, compared with palm oil, decreased the mRNA expression of ChREBP $\beta$. This also likely contributed to the PUFAdependent decrease in lipogenesis. ChREBP but not SREBP-1 targets the Pklr gene encoding liver-type pyruvate kinase. ${ }^{(32)}$ Therefore, down-regulation of the ChREBP signaling pathway may account for reductions in the activity and mRNA levels of pyruvate kinase by diets rich in PUFAs.

In addition to these transcription factors, PPAR $\alpha$ not only affects the expression of genes involved in fatty acid oxidation, but also those related to lipogenesis. Previous studies indicated that the activation of PPAR $\alpha$ is associated with the downregulated expression of the Pklr gene. ${ }^{(34)}$ Dietary GLA oil may strongly activate PPAR $\alpha$, as reflected by the enhanced mRNA expression of its targets. GLA oil, not only compared with palm oil but also with safflower oil, decreased the pyruvate kinase activity and gene expression of pyruvate kinase. Both downregulation of the ChREBP signaling pathway and up-regulation of the PPAR $\alpha$ signaling pathway may account for GLA oildependent marked decreases in pyruvate kinase activities and mRNA levels. Not only SREBP-1c and ChREBP but also PPAR $\alpha$ target the genes for malic enzyme $1^{(35)}$ and stearoyl-CoA desaturase
$1^{(36)}$ to increase their expression. In addition, fatty acid desaturase 1 and 2 genes $^{(37)}$ are also dually regulated by both SREBP-1c and PPAR $\alpha$, although information regarding the role of ChREBP in affecting expression of these genes is not available. GLA oil may have down-regulated SREBP-1c and ChREBP signaling pathways, but up-regulated the PPAR $\alpha$ signaling pathway, and hence induced peculiar changes in mRNA expression of these genes.

Effects of GLA oil on serum and hepatic lipid concentrations. Alterations in hepatic fatty acid synthesis ${ }^{(38)}$ and oxidation $^{(39)}$ modify the availability of fatty acids for the synthesis of triacylglycerol, and in turn, alter VLDL production by the liver. Therefore, a change in the rate of these metabolic processes is crucial in determining serum lipid concentrations. Indeed, alterations in hepatic fatty acid synthesis and oxidation by dietary fats were accompanied by marked changes in serum lipid profiles in the current study. Noticeably, the large increases in hepatic fatty acid oxidation together with the decreases in the parameters for lipogenesis caused by the diets containing GLA oil accompanied marked decreases in serum triacylglycerol and cholesterol levels. We also confirmed that changes in cholesterol levels were ascribable to changes in the serum concentrations of apolipoprotein B-containing lipoproteins. Therefore, it is plausible that the GLA oil markedly reduced the assembly and production of apolipoprotein B-containing VLDL. As the activity and mRNA levels of lipogenic enzymes, except for malic enzyme and pyruvate kinase, were comparable between mice fed safflower or GLA oil, greater reductions in serum triacylglycerol and cholesterol levels in animals fed GLA oil than in those fed safflower oil are mainly ascribable to the promotion of hepatic fatty acid oxidation in mice fed GLA oil. As expected, alterations in fatty acid metabolism by dietary fats also accompanied changes in hepatic lipid levels. Accordingly, oils rich in PUFAs, compared with palm oil, lowered the hepatic triacylglycerol level. Although the differences were not significant, the values were lower in mice fed diets containing GLA oil than in those fed a $100 \mathrm{~g} / \mathrm{kg}$ safflower oil diet. As the diets containing GLA oil, compared with diets containing either $100 \mathrm{~g} / \mathrm{kg}$ of palm or safflower oil, decreased the hepatic concentration of cholesterol, GLA oil may alter the hepatic cholesterol metabolism. The diets containing GLA oil, compared with palm and safflower oils, increased liver weight accompanying the elevation of hepatic phospholipid levels, which may reflect the proliferation of mitochondria and peroxisomes. Previous studies demonstrated that agonists of PPAR $\alpha$ increased hepatic phospholipid levels. ${ }^{(40)}$

We also found that GLA oil, compared with both palm and safflower oils, increased serum cholesterol and phospholipid levels in the HDL fraction, indicating that GLA oil facilitates the reverse cholesterol transport system. Therefore, GLA oil consumption induces physiological changes meritorious in preventing arteriosclerosis. However, this was rather unexpected because the present study indicated that dietary GLA oil strongly activated PPAR $\alpha$. Agonists of PPAR $\alpha$ were reported to increase HDL formation through the enhanced expression of apolipoproteins AI and A $\alpha$ in humans. However, a PPAR agonist (fenofibrate) as well as fish oil (an oil to activate PPAR $\alpha$ ) caused an approximately $30 \%$ decrease in hepatic apolipoprotein AI mRNA levels in mice. ${ }^{(41)}$ Consistent with this, we observed that GLA oil, compared with palm oil, slightly but significantly decreased hepatic apolipoprotein AI mRNA levels in the present study. Further studies to examine the effects of GLA oil on HDL formation and metabolism are required to clarify the mechanisms underlying GLA oildependent changes in HDL-lipid levels.

In conclusion, dietary oil rich in GLA, compared with saturated fat (palm oil) and an oil rich in linoleic acid (safflower oil), strongly increased hepatic fatty acid oxidation in hyperlipidemic mice deficient in apoE expression. Oils containing high levels of PUFAs compared with palm oil reduced the activity and mRNA levels of hepatic lipogenic enzymes. However, in general, GLA 
and safflower oils were comparable in affecting these parameters. GLA oil, compared with both palm and safflower oils, decreased serum lipid concentrations which may be due to alterations of hepatic fatty acid oxidation and synthesis.

\section{Author Contributions}

TI: study concept and design; acquisition of data; analysis and interpretation of data; drafting of the manuscript; obtained funding.

IO: acquisition of data; analysis and interpretation of data.

\section{Acknowledgments}

This study was supported by a Grant-in-Aid for scientific research (KAKENHI Scientific Research C, No. 22580143) from the Japan Society for the Promotion of Science. Expert technical assistance by Mrs. Yu Uchiyama, Yukako Yasuda, Noe Yamaguchi and Marino Yamamichi was greatly appreciated.

\section{References}

1 Takada R, Saitoh M, Mori T. Dietary $\gamma$-linolenic acid-enriched oil reduces body fat content and induces liver enzyme activities relating to fatty acid $\beta$ oxidation in rats. J Nutr 1994; 124: 469-474.

2 Kumamoto T, Ide T. Comparative effects of $\alpha$ - and $\gamma$-linolenic acids on rat liver fatty acid oxidation. Lipids 1998; 33: 647-654.

3 Takahashi Y, Ide T, Fujita H. Dietary $\gamma$-linolenic acid in the form of borage oil causes less body fat accumulation accompanying an increase in uncoupling protein $1 \mathrm{mRNA}$ level in brown adipose tissue. Comp Biochem Physiol B Biochem Mol Biol 2000; 127: 213-222.

4 Huang YS, Manku MS, Horrobin DF. The effects of dietary cholesterol on blood and liver polyunsaturated fatty acids and on plasma cholesterol in rats fed various types of fatty acid diet. Lipids 1984; 19: 664-672.

5 Sugano M, Ishida T, Ide T. Effects of various polyunsaturated fatty acids on blood cholesterol and eicosanoids in rats. Agric Biol Chem 1986; 50: 2335 2340.

6 Fukushima M, Akiba S, Nakano M. Comparative hypocholesterolemic effects of six vegetable oils in cholesterol-fed rat. Lipids 1996; 31: 415-419.

7 Dasgupta S, Bhattacharyya DK. Dietary effect of $\gamma$-linolenic acid on the lipid profile of rat fed erucic acid rich oil. J Oleo Sci 2007; 56: 569-577.

8 Singer P, Hoffmann P, Beitz J, Förster W, Wirth M, Gödicke W. Serum triglycerides and HDL cholesterol from SHR after evening primrose oil and other polyunsaturated fats. Prostaglandins Leukot Med 1986; 22: 173-177.

9 Ford I, Cotter MA, Cameron NE, Greaves M. The effects of treatment with $\alpha$-lipoic acid or evening primrose oil on vascular hemostatic and lipid risk factors, blood flow, and peripheral nerve conduction in the streptozotocindiabetic rat. Metabolism 2001; 50: 868-875.

10 Engler MM, Engler MB, Erickson SK, Paul SM. Dietary gamma-linolenic acid lowers blood pressure and alters aortic reactivity and cholesterol metabolism in hypertension. J Hypertens 1992; 10: 1197-1204.

11 Fan YY, Ramos KS, Chapkin RS. Dietary $\gamma$-linolenic acid suppresses aortic smooth muscle cell proliferation and modifies atherosclerotic lesions in apolipoprotein E knockout mice. J Nutr 2001; 131: 1675-1681.

12 Asset G, Baugé E, Fruchart JC, Dallongeville J. Lack of triglyceridelowering properties of fish oil in apolipoprotein e-deficient mice. Arterioscler Thromb Vasc Biol 2001; 21: 401-406.

13 Wang HH, Hung TM, Wei J, Chiang AN. Fish oil increases antioxidant enzyme activities in macrophages and reduces atherosclerotic lesions in apoE-knockout mice. Cardiovasc Res 2004; 61: 169-176.

14 Ide T, Kobayashi H, Ashakumary L, et al. Comparative effects of perilla and fish oils on the activity and gene expression of fatty acid oxidation enzymes in rat liver. Biochim Biophys Acta 2000; 1485: 23-35.

15 Hong DD, Takahashi Y, Kushiro M, Ide T. Divergent effects of eicosapentaenoic and docosahexaenoic acid ethyl esters, and fish oil on hepatic fatty acid oxidation in the rat. Biochim Biophys Acta 2003; 1635: 29-36.

16 Kim HJ, Takahashi M, Ezaki O. Fish oil feeding decreases mature sterol regulatory element-binding protein 1 (SREBP-1) by down-regulation of SREBP-1c mRNA in mouse liver. A possible mechanism for down-regulation of lipogenic enzyme mRNAs. J Biol Chem 1999; 274: 25892-25898.

\section{Abbreviations}

apoE apolipoprotein E

ChREBP carbohydrate response element binding protein

DHA docosahexaenoic acid

EPA eicosapentaenoic acid

GLA $\quad \gamma$-linolenic acid

G6pdx glucose-6-phosphate dehydrogenase X-linked

HDL high-density lipoprotein

LDL low-density lipoprotein

PPAR $\alpha$ peroxisome proliferator-activated receptor $\alpha$

Pklr Pyruvate kinase liver and red blood cell

PUFA polyunsaturated fatty acid

SREBP sterol regulatory element binding protein

VLDL very low-density lipoprotein

\section{Conflict of Interest}

No potential conflicts of interest were disclosed.

17 Riediger ND, Othman R, Fitz E, Pierce GN, Suh M, Moghadasian MH. Low n-6:n-3 fatty acid ratio, with fish- or flaxseed oil, in a high fat diet improves plasma lipids and beneficially alters tissue fatty acid composition in mice. Eur J Nutr 2008; 47: 153-160.

18 Suzuki-Kemuriyama N, Matsuzaka T, Kuba M, et al. Different effects of eicosapentaenoic and docosahexaenoic acids on atherogenic high-fat dietinduced non-alcoholic fatty liver disease in mice. PLoS One 2016; 11: e0157580.

19 Ide T, Takahashi Y, Kushiro M, Tachibana M, Matsushima Y. Effect of n-3 fatty acids on serum lipid levels and hepatic fatty acid metabolism in BALB/ c.KOR-Apoe ${ }^{\text {shl }}$ mice deficient in apolipoprotein E expression. J Nutr Biochem 2004; 15: 169-178.

20 Reeves PG, Nielsen FH, Fahey GC Jr. AIN-93 purified diets for laboratory rodents: final report of the American Institute of Nutrition ad hoc writing committee on the reformulation of the AIN-76A rodent diet. $J$ Nutr 1993; 123: 1939-1951.

21 Chomczynski P, Sacchi N. Single-step method of RNA isolation by acid guanidium thiocyanate-phenol-chloroform extraction. Anal Biochem 1987; 162: $156-159$.

22 Ide T. Interaction of fish oil and conjugated linoleic acid in affecting hepatic activity of lipogenic enzymes and gene expression in liver and adipose tissue. Diabetes 2005; 54: 412-423.

23 Ide T, Okamatsu H, Sugano M. Regulation by dietary fats of 3-hydroxy-3methylglutaryl-Coenzyme A reductase in rat liver. J Nutr 1978; 108: 601612.

24 Demacker PN, Vos-Janssen HE, Hijmans AG, van't Laar A, Jansen AP. Measurement of high-density lipoprotein cholesterol in serum: comparison of six isolation methods combined with enzymic cholesterol analysis. Clin Chem 1980; 26: 1780-1786.

25 Pearson DJ, Chase JFA, Tubbs PK. The Assay of (-)-carnitine and its O-acyl derivatives. Method Enzymol 1969; 14: 612-622.

26 Pawlak M, Lefebvre P, Staels B. Molecular mechanism of PPAR $\alpha$ action and its impact on lipid metabolism, inflammation and fibrosis in non-alcoholic fatty liver disease. $J$ Hepatol 2015; 62: 720-733.

27 Corton JC, Apte U, Anderson SP, et al. Mimetics of caloric restriction include agonists of lipid-activated nuclear receptors. J Biol Chem 2004; 279: 46204-46212.

28 Motojima K, Passilly P, Peters JM, Gonzalez FJ, Latruffe N. Expression of putative fatty acid transporter genes are regulated by peroxisome proliferatoractivated receptor $\alpha$ and $\gamma$ activators in a tissue- and inducer-specific manner. J Biol Chem 1998; 273: 16710-16714.

29 Wen G, Ringseis R, Eder K. Mouse OCTN2 is directly regulated by peroxisome proliferator-activated receptor $\alpha(\operatorname{PPAR} \alpha)$ via a PPRE located in the first intron. Biochem Pharmacol 2010; 79: 768-776.

30 Wen G, Kühne H, Rauer C, Ringseis R, Eder K. Mouse $\gamma$-butyrobetaine dioxygenase is regulated by peroxisome proliferator-activated receptor $\alpha$ through a PPRE located in the proximal promoter. Biochem Pharmacol 2011; 82: $175-183$. 
31 Wen G, Ringseis R, Rauer C, Eder K. The mouse gene encoding the carnitine biosynthetic enzyme 4-N-trimethylaminobutyraldehyde dehydrogenase is regulated by peroxisome proliferator-activated receptor $\alpha$. Biochim Biophys Acta 2012; 1819: 357-365.

32 Iizuka $\mathrm{K}$. The transcription factor carbohydrate-response element-binding protein (ChREBP): a possible link between metabolic disease and cancer. Biochim Biophys Acta 2017; 1863: 474-485.

33 Yahagi N, Shimano H, Hasty AH, et al. A crucial role of sterol regulatory element-binding protein-1 in the regulation of lipogenic gene expression by polyunsaturated fatty acids. J Biol Chem $1999 ; 274$ : 35840-35844.

$34 \mathrm{Xu} \mathrm{J}$, Christian B, Jump DB. Regulation of rat hepatic L-pyruvate kinase promoter composition and activity by glucose, $n-3$ polyunsaturated fatty acids, and peroxisome proliferator-activated receptor- $\alpha$ agonist. $J$ Biol Chem 2006; 281: 18351-18362.

35 Castelein H, Gulick T, Declercq PE, Mannaerts GP, Moore DD, Baes MI. The peroxisome proliferator activated receptor regulates malic enzyme gene expression. J Biol Chem 1994; 269: 26754-26758.
36 Paton CM, Ntambi JM. Biochemical and physiological function of stearoylCoA desaturase. Am J Physiol Endocrinol Metab 2009; 297: E28-E37.

37 Matsuzaka T, Shimano H, Yahagi N, et al. Dual regulation of mouse $\Delta^{5}$ - and $\Delta^{6}$-desaturase gene expression by SREBP-1 and PPAR $\alpha$. J Lipid Res 2002; 43: 107-114.

38 Windmueller HG, Spaeth AE. De novo synthesis of fatty acid in perfused rat liver as a determinant of plasma lipoprotein production. Arch Biochem Biophys 1967; 122: 362-369.

39 Ide T, Ontko JA. Increased secretion of very low density lipoprotein triglyceride following inhibition of long chain fatty acid oxidation in isolated rat liver. J Biol Chem 1981; 256: 10247-10255.

40 Yanagita T, Satoh M, Enomoto N, Sugano M. Di(2-ethylhexyl)phthalate enhances hepatic phospholipid synthesis in rats. Biochim Biophys Acta 1987; 919: 64-70.

41 Dallongeville J, Baugé E, Tailleux A, et al. Peroxisome proliferator-activated receptor $\alpha$ is not rate-limiting for the lipoprotein-lowering action of fish oil. $J$ Biol Chem 2001; 276: 4634-4639. 